\title{
Extraction and immediate placement of root analogue zirconia implants: an overview
}

\author{
D.R Prithviraj ${ }^{1}$, K.M. Regish ${ }^{2}$, Sharma Deeksha ${ }^{2}$, D.P. Shruthi ${ }^{3}$ \\ ${ }^{1}$ M.D.S. Professor and Head. Dept. of prosthodontics Govt. Dental College and Research Institute, Bangalore, Victoria Hospital \\ Campus, Fort, Bangalore. \\ ${ }^{2}$ Post graduate student. Dept. of prosthodontics Govt. Dental College and Research Institute, Bangalore, Victoria Hospital Cam- \\ pus, Fort, Bangalore. \\ ${ }^{3}$ B.D.S. Govt. Dental College and Research Institute, Bangalore. Victoria Hospital Campus, Fort, Bangalore.
}

Correspondence:

\#7a, gdcri, victoria hospital campus,

Fort, Bangalore, Karnataka,India-02

E-mail: prithvidr@yahoo.com

Received: $23 / 12 / 2010$ Accepted: $08 / 05 / 2011$
Prithviraj DR, Regish KM, Deeksha S, Shruthi DP. Extraction and immediate placement of root analogue zirconia implants: an overview. J Clin Exp Dent. 2011;3(3):e240-5.

http://www.medicinaoral.com/odo/volumenes/v3i3/jcedv3i3p240.pdf

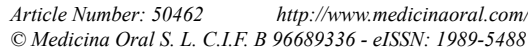

\begin{abstract}
Dental implants constitute a well-established approach for replacement of lost teeth with titanium being the most favored material for implantation. However, titanium has its limitations in esthetically demanding cases and neither the form nor material of such implants has changed much over the past 40 years. Immediate implantation has been introduced to overcome the disadvantages of conventional implantation which in turn has many disadvantages owing to the incongruence of the implant to the extraction socket. Today, there is scientific evidence that zirconia dental implants osseointegrate well and offer many advantages over titanium implants. The successful use of zirconia ceramics in orthopedic surgery led to a demand for dental zirconium-based implant systems. Because of its excellent biomechanical characteristics, biocompatibility, and bright tooth-like color, zirconia (zirconium dioxide, $\mathrm{ZrO} 2$ ) has the potential to become a substitute for titanium as dental implant material. In addition, there are previous reports on the successful use of Zirconia as root-analogue implants by reproducing the contours of the extracted tooth.

This article presents an overview of the technique of using root analogue zirconia dental implants as an immediate implantation material which are replicas of the extracted tooth and therefore truly anatomical and socket friendly.
\end{abstract}

Key words: immediate implantation, root analogue implants, custom made implants, Zirconia, Zirconia implants. 


\section{Introduction}

Replacement of lost teeth using oral implants is an accepted treatment modality with well documented, high long-term success rates of up to between $90 \%$ and $100 \%$ at 10 -year follow up (1). Titanium and titanium alloys are widely used for fabrication of dental implants (2). Expectations regarding esthetics in dentistry are growing and research in the field of all ceramic materials for restoration of natural dentition and dental implants has intensified. To improve the esthetic aspect of dental implants, a ceramic material, zirconia, was introduced (3). Immediate implant placement has its own advantages and the problem of incongruence associated with it can be rectified by employing a novel approach using custom-made root analogue implants placed into the extraction socket. By adapting the root to the extraction socket instead of adapting the bone to a preformed standardized implant they reduced the bone and soft tissue trauma (4).

Zirconia-based implants were introduced into dental implantology as an alternative to titanium implants. Owing to its ability to be milled into the shape of the natural tooth root and be placed immediately following extraction, excellent biomechanical characteristics, biocompatibility, and bright tooth-like color, Zirconia has the potential to become a substitute for titanium as dental implant material (2).

\section{Search Strategy}

A PubMed search of English literature was conducted up to January 2010 using the terms: implants ('immediate placement' or 'delayed placement' or 'early placement' or 'delayed-immediate' or 'extraction sockets'), 'immediate extraction sockets', 'immediate implants', 'root analogue implants', 'Zirconia implants'. Additionally, the bibliographies of 7 previous reviews as well as articles published in Clinical Oral -Implants Research, International Journal of Oral and Maxillofacial Implants, International Journal of Oral and Maxillofacial surgery, International Journal of Prosthodontics, Journal of Periodontology, Journal of Oral Implantology, Journal of prosthetic dentistry, International journal of prosthodontics, Journal of esthetic dentistry, British dental journal, Dental update, New York state dental journal, Head and face medicine were manually searched.

\section{Immediate Placement of Zirconia Implants}

There are various recommendations regarding timing of implant placement after tooth extraction. The implant can be placed,

Immediately following the extraction during the same surgical procedure (Immediate implant placement)

Following a delay of 2-6 weeks (late implant placement).

Following a delay of 3-6 months (delayed implant place- ment) to allow bone healing.

Months or years following the tooth loss(5).

The predictability of aesthetic success depends on the tissue loss present at the initiation of treatment. The greater the amount of bone and soft tissue loss, the more difficult it becomes to produce an ideal aesthetic result(6).

In 2004, Kohal and Klaus reported the first clinical case report of placement of zirconia implant immediately after extraction. They presented a case in which an all-ceramic custom-made zirconia implant crown system was used as the replacement for a single tooth. They extracted a maxillary central incisor and immediately implanted a zirconia implant with successful outcomes(7).

Since zirconia implants are one-piece implants that cannot be left to heal submerged and can be easily provisionalised after their placement, it would be interesting to understand whether it is preferable to keep them out of occlusion during the osseointegration phase or if it is possible to immediately put them into function without an increased risk of failure. While there is abundant literature on titanium implant (8), little is known about the outcome of zirconia implants $(8,9)$.

In a randomised controlled clinical trial by Gioacchino et al for immediate placement of zirconia implant on an effort to compare immediate occlusal versus non-occlusal loading of single zirconia implants, teeth with hopeless prognosis were extracted using the least traumatic technique possible. Implant sites were under-prepared to obtain an insertion torque $>35 \mathrm{Ncm}$ and the surgical unit was settled with a torque of $35 \mathrm{Ncm}$. Various lengths of Single one-piece zirconia implants were used. In aesthetic areas, immediate post-extractive implants were placed 1 to $2 \mathrm{~mm}$ deeper than in other areas. In case of residual gaps of $>2 \mathrm{~mm}$ between the alveoli and the implant, autogenous bone or bone substitutes could be used to fill the gap. The results of the study did not provide a conclusive answer to whether immediate placed zirconia implants with nonocclusal loading may decrease implant failures. It is possible that success rates are not profoundly influenced by whether or not immediately placed and loaded implants are put into functional occlusion. Conversely, immediately placed and loaded zirconia implants placed in post-extractive sites were found to be at higher risk of failure than implants placed in healed sites(10).

In an experimental study," the "osseocoaptation" qualities of three different kinds of implants (titanium. zirconia and alumina) with two bone fillers were evaluated; it has been reported that there was no significant statistical difference among the three types of implants(11). Scarano et al. analyzed the bone response to immediately placed zirconia ceramic implants in rabbits. They concluded that the mean bone implant surface was about $68.4 \%$ and that the bone-implant interface around the zirconia implant is similar to that observed around tita- 
nium implants(12).

In a clinical report of immediate placement of Zirconia implant by Oliva et al, the surgical treatment started with atraumatic teeth and root extractions using scalpels and forceps. The drilling sequence used two pilot drills followed by twist drills. Special care was taken to give the drills the appropriate inclination to follow the incisal edge of the missing teeth. A profile drill was used to finalize the shape of the implant site. The implants were inserted at the contra-angle using a special key. Fifteen days postsurgery, the appearance of the soft tissues was very good and little inflammation was visible. No problems were reported during the 3-month healing period(13).

In a case report by Oliva et al on Ovoid Zirconia Implants for Anatomic Design for Premolar Replacement, a CeraRoot Type 14 Zirconia implant was used. This is an ovoid implant with an acid-ethced surface that must be placed with a press-fit technique using an inserting key with a rubber end and a hammer. Three small percussions were needed to firmly adapt the implant into the site. As judged from the occlusal view, the implant completely filled the extraction socket, ensuring perfect osseointegration of the implant.

The appropriate selection of cases is crucial when using zirconia implants. Only cemented restorations can be used to restore these situations. For this reason the implant must be placed in the perfect position and inclination. In addition, the patient should have a favorable and stable occlusion to avoid placing undue stress on implants(14). (Table 1,(15))

1. If acute infection, preoperative antibiotic therapy
2. No purulent exudate at extraction site
3. Patient warned of possible staged or delayed procedure
4. Surgeon's decision, go or no go, at time of extraction
5. Atraumatic surgical removal
a. Section with high-speed bur
b. Periotome removal
6. Lingual/palatal line of preparation and insertion of im-
plant
7. 2.0 mm longer than root
8. Implant must be immobilized at final placement
9. Adequate soft-tissue closure

Table 1. Considerations for Immediate Implantation (15)

\section{Zirconia a root analogue custom implant mate- rial}

In immediate implantation of Zirconia, following tooth extraction, however, a socket often presents dimensions that may be considerably greater than the diameter of a conventional implant. Hence, after implant installation a gap may occur in the marginal part of the recipient site (16).

Traditional techniques allowing implant placement in extraction sockets use either high diameter implants in surgically enlarged sockets or grafting (17) and/or regenerative procedures around primarily stabilized implants (18); however, none of these allow immediate loading. Implant immobilization in the extraction socket is important to preserve the surrounding bone tissue, which is usually affected by the placement of large implants especially designed for this purpose. Strong immobilization is necessary to obtain good osseointegration (19).

The concept of replacing teeth with custom-made rootanalogue implants was reported as early as 1969; however, the autopolymerised and heat processed polymethacrylate utilized to fabricate the tooth analogue was encapsulated by soft tissue rather than osseointegrated (20).

Lundgren and colleagues reintroduced the idea of rootanalogue implants in 1922 using titanium which offered satisfactory results $(4,21)$.

In a recently developed root analogue implant system, $\mathrm{CAD} / \mathrm{CAM}$ was used for the fabrication of the root analogue which allowed the immediate replacement of teeth which had to be extracted $(22,23)$. Lundgren concluded that this system osseointegrated with a high degree of predictability and the quality of bone-to-implant contact was high enough to function well. However; long surgical time was needed in immediate replacement with this system (24).

Today, the combination of anatomically oriented implant designs, new biomaterials such as zirconia ceramics, and surface technologies has resulted in dental implants that are specially designed to replace each individual tooth (14).

Partially stabilized zirconia, which is comparable to the highest values for oxide ceramics, has been introduced as a new ceramic implant material (25). Yttria-stabilized tetragonal zirconia polycrystal (YTZP) exhibits a very high flexural strength (900 to 1,200 MPa), a favorable fracture toughness (KIC7 to $1 \mathrm{MPam}^{-1}$ ), and a suitable Young's modulus (210 GPa) (9). Zirconia is a strong biomaterial and is a unique dental ceramic due to its ability to undergo transformation toughening(26). The mechanical properties with high-fracture resistance and the elastic modulus of zirconia might also contribute to the bone healing and provide mechanical stability. Moreover, this material is highly radiopaque (25).

Biocompatibility has been evaluated using in vitro tests performed on different materials (e.g., powders or compacts, different impurity levels) with different cell lines in different biologic conditions (e.g., fibroblasts, phytohemagglutinin-stimulated lymphocytes), with similar positive results. Furthermore, in vitro carcinogenicity and mutagenicity tests showed negative results (9).

The quality of the bone-implant contact was comparable to that of alumina implants and was influenced by implantation site and implant surface modifications. In an animal study, osseointegration was evaluated at 4 
weeks to 24 months after insertion in different animal models and sites and under different loading conditions. The mean bone implant contact ratio was above $60 \%$ in almost all experimental groups, indicating successful osseointegration. In those investigations that used titanium implants as a control, zirconia implants were comparable to or even better than titanium implants (2).

Davies emphasized the importance of implant surface design and microtopography to achieve what he called "de novo bone formation" on the implant surface itself, in addition to the ingrowth of bone from adjacent bone surfaces. Roughened surfaces have been shown to support osteoconduction leading to bone formation on the implant surface (27). Furthermore, Sennerby et al found that Y-TZP implants with a moderately roughened surface showed a fourfold to fivefold increase in resistance to torque forces compared with machined Y-TZP implants after 6 weeks of healing (28).

In a study by Gahlert et al regarding the Biomechanical and histomorphometric comparison between zirconia implants with varying surface textures and a titanium implant in the maxilla of miniature pigs, the substance of $\mathrm{ZrO} 2$ implants passed following steps during the production process: isostatic dry pressing, sintering, hot isostatic pressing (HIP) process, shaping and polishing by diamond tools. The study confirmed that surface characteristics have an important influence on bone integration of $\mathrm{ZrO} 2$ implants, though osseointegration into bone is evident (29).

In a clinical case report reported by Kohal and Klaus regarding placement of zirconia implant immediately after extraction, a custom-made zirconia dental implant was used. The implant was fabricated ad modum ReImplant. Briefly, after having evaluated the radiographs (panoramic view, conventional tomograms), a copy of the final implant was reconstructed using selfcuring acrylic resin. This copy was mounted into the ReImplant scanning unit and scanned. The acrylic resin copy was then exchanged for a highly isostatic pressed zirconia cylinder. According to the scanning data, a high-speed handpiece incorporated into the ReImplant milling unit cut the final implant out of the zirconia cylinder (7).

In an investigation by Kohal, Klaus and Strub to test zirconia implants restored with different all-ceramic crowns with the titanium implant serving as control, an extracted maxillary central left incisor served as a model for the fabrication of the titanium and zirconia implants. The root was transformed into a titanium implant using the ReImplants Unit. Commercially pure titanium grade 2 was used as implant material. The tooth root was scanned by the system immanent laser, and the obtained data were stored in the computer unit of the system. Then, the tooth root was replaced by a cylindrical titanium blank and the milling unit processed the implant according to the computer data. For the ceramic implants, prefabri- cated partially stabilized zirconia cylinders with a length of $20 \mathrm{~mm}$ and a diameter of $10 \mathrm{~mm}$ were used. The titanium implant model obtained from the ReImplants Unit was copied into a zirconia implant using the Celays System (30).

In a clinical report by Pirker and Kocher, they selected root-identical implants with significant modifications by 1) using zirconia for its excellent biocompatibility and improved esthetic results; 2) adding micro-retentions to the entire root surface and macro-retentions strictly limited to the interdental space to get beyond primary stability and improve osseointegration; 3) reducing the diameter of the implant next to the thin cortical bone to avoid fracture and pressure induced bone loss; and 4) choosing a single-stage implantation resulting in immediate, albeit limited, functional load via the crown stump for prevention of bone resorption. After extraction the root was laser scanned and macro retentions were designed. In addition a crown stump was designed for later connection to the crown. The implant was then milled from a zirconium dioxide block, and the surface roughened by sandblast and sintered for $8 \mathrm{~h}$ to achieve the desired mechanical properties. On day 4 the custom-made individualized root analogue implant was then placed into the socket under finger pressure and subsequent gentle tapping with a hammer and a mallet to achieve the primary stability. At the control visit 10 days later a clinically healthy marginal area was present, and no postoperative pain or swelling was reported. At 2-year follow up the patient presented with a stable implant, unchanged peri- implant marginal bone level as monitored by radiographs and soft-tissue parameters, and no bleeding on probing. The single-stage implant approach with a crown stump lead to an early functional load allowing for osseointegration while preventing bone resorption (1).

In a follow up study by the same authors, they concluded that by introducing significant modifications, such as macro retentions and implant diameter reduction next to the cortical bone, primary stability and excellent osseointegration of immediate root analogue zirconia implants can be achieved, while preventing unaesthetic bone resorption. This novel approach could form an alternative method for replacing teeth immediately after extraction. The preliminary results of human trials with multi rooted teeth indicate that this method might be applied to all teeth (4).

Further in a case report published by Pirker, Wiedemann, Lidauer, Kocher on placement of immediate, single stage, truly anatomic zirconia implant in lower molar replacement they used a modified, truly anatomic, root-analogue zirconia implant for immediate replacement of a two-rooted, left first mandibular molar. A good functional and aesthetic result was achieved with minimal bone resorption and soft tissue recession at 30 
months follow-up (31).

However the technique of immediate placement of root analogue zirconia implants restricts itself to the cases of extraction of periodontally sound tooth with a sufficiently deep socket, atraumatic extractions, sufficient bone support, and absence of periapical pathologies.

\section{Conclusion}

Presently, pure titanium is the material of choice for dental implants. This material has been used for about 30 years as an implant substrate and has shown high rates of success. However, there is the disadvantage of grey metallic components showing through the mucosa or becoming visible in cases of soft tissue recession and an increasing number of patients are asking for metal-free treatment options. One of the possible solutions would be to make implants from tooth-colored materials, such as ceramics. Favorable mechanical, biological, esthetic properties, potential for osseointegration and the ability to customize it and place it immediately following extraction make zirconia, a ceramic material of choice for dental implants in recent times.

The problem associated with immediate implant placement using these conventional implants is the incongruence with the extraction socket.

Today, the combination of anatomically oriented implant designs, new biomaterials such as zirconia ceramics, and surface technologies has resulted in dental implants that are specially designed to replace each individual tooth. Significant modifications such as macro-retentions seem to indicate that primary stability and excellent osseointegration of such implants can be achieved, while preventing unaesthetic bone resorption leading to unaesthetic results.

Zirconia implants are mainly manufactured as only 1piece Y-TZP implants. To establish an excellent esthetic result, especially in the anterior region, these implants must be placed at a perfect angulation and apicocoronal position. The information on 2-part Y-TZP implants is limited to 1 in vitro study in which the implants restored with 2 different all-ceramic crowns did not sufficiently withstand static and cyclic loading and were thus not recommended for clinical use.

However, further studies are needed about this type of implant, with a larger sample and better monitoring.

\section{References}

1. Pirker W, Kocher A. Immediate, non-submerged, root-analogue zirconia implant in single tooth replacement. Int J Oral Maxillofac Surg. 2008; 37: e293-5.

2. Depprich R, Zipprich H, Ommerborn M, Naujoks C, Wiesmann $\mathrm{HP}$, Kiattavorncharoen $\mathrm{S}$ et al. Osseointegration of zirconia implants compared with titanium: an in vivo study. Head Face Med. 2008; 11: 4:30.

3. Aydin C, Yilmaz H, Ata SO. Single-tooth zirconia implant located in anterior maxilla. A clinical report. N Y State Dent J. 2010; 79:
30-3.

4. Pirker W, Kocher A. Immediate, non-submerged, root-analogue zirconia implants placed into single-rooted extraction sockets: 2-year follow-up of a clinical study. Int J Oral Maxillofac Surg. 2009; 8: 1127-32.

5. Palmer RM, Palmer PJ, Baker P. Immediate and Early placement implants and restorations. Dent Update. 2006; 33: 262-4, 266-8.

6. Jivraj S, Chee W. Treatment planning of implants in the aesthetic zone. Br Dent J. 2006; 22: 77-89.

7. Kohal RJ, Klaus G. A zirconia implant-crown system: a case report. Int J Periodontics Restorative Dent. 2004; 24: 147-53.

8. Esposito M, Murray-Curtis L, Grusovin MG, Coulthard P, Worthington HV. Interventions for replacing missing teeth: different types of dental implants. Cochrane Database Syst Rev. 2007; 17: CD003815.

9. Wenz HJ, Bartsch J, Wolfart S, Kern M. Osseointegration and clinical success of zirconia dental implants: a systematic review. Int J Prosthodont 2008; 21: 27-36.

10. Cannizarro G, Torchio C, Felice P, Leone M, Esposito M. Immediate occlusal versus non-occlusal loading of single zirconia implants. A multicentre pragmatic randomised clinical trial. Eur J Oral Implantol. 2010; 3: 111-20.

11. Dubruille JH, Viguier E, Le Naour G, Dubruille MT, Auriol M, Le Charpentier Y. Evaluation of combinations of titanium, zirconia, and alumina implants with 2 bone fillers in the dog. Int J Oral Maxillofac implants 1999; 14: 271-7.

12. Scarano A, DiCarlo F, Quaranta M. Piattelli A. Bone response to zirconia ceramic implants: an experimental study in rabbits. J Oral Implantol 2003; 29: 8-12.

13. Oliva J, Oliva X, Oliva JD. Zirconia implants and all-ceramic restorations for the esthetic replacement of the maxillary central incisors. Eur J Esthet Dent. 2008; 3: 174-85.

14. Oliva J, Oliva X, Oliva JD. Ovoid zirconia implants: Anatomic design for premolar replacement. Int J Periodontics Restorative Dent. 2008; 28: 609-15.

15. Glickman RS, Bae R, Karlis V. A model to evaluate bone substitutes for immediate implant placement. Implant Dent. 2001; 10: 209-15.

16. Botticelli D, Berglundh T, Buser D, Lindhe J. The jumping distance revisited. Clin Oral Implants Res. 2003; 14: 35-42.

17. Gotfredsen K, Nimb L, Hjorting-Hansen E. Immediate implant placement using a biodegradable barrier, polyhydroxybutyratehydroxyvalerate reinforced with polyglactin 910 . An experimental study in dogs. Clin Oral Implants Res 1994; 5: 83-91.

18. Kohal RJ, Mellas P, Hürzeler MB, Trejo PM, Morrison E, Caffesse RG. The effects of guided bone regeneration and grafting on implants placed into immediate extraction sockets. An experimental study in dogs. J Periodontol 1998; 69: 927-37.

19. Douglass GL, Merin RL. The immediate dental implant. J Calif Dent Assoc 2002; 30: 362-5, 368-74.

20. Lundgren D, Rylander H, Andersson M, Johansson C, Albrektsson T. Healing-in of root analogue titanium implants placed in extraction sockets. An experimental study in the beagle dog. Clin Oral Implants Res 1992; 3:136-43.

21. Carlsson L, Röstlund T, Albrektsson B, Albrektsson T. Removal torques for polished and rough titanium implants. Int J Oral Maxillofac Implants 1988; 3: 21-4.

22. Kohal RJ, Hürzeler MB, Mota LF, Klaus G, Caffesse RG, Strub RJ. Custom made root analogue titanium implants placed into extraction sockets. Clin Oral Impl Res 1997; 8: 386-92.

23. Strub JR, Kohal R, Klaus G, Ferraresso F. The Re Implant system for immediate implant placement. J Esthet Dent 1997; 9: 187-96.

24. Schropp L, Isidor F. Timing of implant placement relative to tooth extraction. J Oral Rehabil. 2008; 35 Suppl 1: 33-43.

25. Akagawa Y, Ichikawa Y, Nikai H, Tsuru H. Interface histology of unloaded and early loaded partially stabilized zirconia endosseous implant in initial bone healing. J Prosthet Dent. 1993; 69: 599604.

26. Dunn DB. The use of a zirconia custom implant supported fixed 
partial denture prosthesis to treat implant failure in the anterior maxilla: A clinical report. J Prosthet Dent. 2008; 100: 415-21.

27. Davies JE. Mechanisms of endosseous integration. Int J Prosthodont 1998; 11: 391-401.

28. Sennerby L, Dasmah A, Larsson B, Iverhed M. Bone tissue responses to surface-modified zirconia implants: A histomorphometric and removal torque study in the rabbit. Clin Implant Dent Relat Res. 2005; 7 Suppl 1: S13-20.

29. Gahlert M, Gudehus T, Eichhorn S, Steinhauser E, Kniha H, Erhar$\mathrm{dt}$ W. Biomechanical and histomorphometric comparison between zirconia implants with varying surface textures and a titanium implant in the maxilla of miniature pigs. Clin Oral Implants Res. 2007; 18: 662-8.

30. Kohal RJ, Klaus G, Strub JR. Zirconia-implant-supported all-ceramic crowns withstand long-term load: a pilot investigation. Clin Oral Implants Res. 2006; 17: 565-71.

31. Pirker W, Wiedemann D, Lidauer A, Kocher AA. Immediate, single stage, truly anatomic zirconia implant in lower molar replacement: A case report with 2.5 years follow-up. Int J Oral Maxillofac Surg. 2010 Sep 10. [Epub ahead of print] 